\title{
Traditional Risk Factors of Acute Coronary Syndrome in Four Different Male Populations - Total Cholesterol Value Does Not Seem To Be Relevant Risk Factor
}

\author{
J. A. HUBACEK ${ }^{1}$, V. STANEK ${ }^{2}$, M. GEBAUEROVA ${ }^{2}$, V. ADAMKOVA ${ }^{3}$, \\ V. LESAUSKAITE ${ }^{4}$, D. ZALIADUONYTE-PEKSIENE ${ }^{5}$, A. TAMOSIUNAS ${ }^{4}$, \\ A. SUPIYEV ${ }^{6}$, A. KOSSUMOV ${ }^{6}$, A. ZHUMADILOVA ${ }^{7}$, J. PITHA ${ }^{1,8}$
}

${ }^{1}$ Department of Experimental Medicine, Institute for Clinical and Experimental Medicine, Prague, Czech Republic, ${ }^{2}$ Department of Cardiology, Institute for Clinical and Experimental Medicine, Prague, Czech Republic, ${ }^{3}$ Department of Preventive Cardiology, Institute for Clinical and Experimental Medicine, Prague, Czech Republic, ${ }^{4}$ Institute of Cardiology, Medical Academy, Lithuanian University of Health Sciences, Kaunas, Lithuania, ${ }^{5}$ Department of Cardiology, Medical Academy, Lithuanian University of Health Sciences, Kaunas, Lithuania, ${ }^{6}$ Laboratory of Epidemiology and Public Health, Center for Life Sciences, National Laboratory Astana, Nazarbayev University, Astana, Kazakhstan, ${ }^{7}$ Department of Biology, School of Science and Technology, Nazarbayev University, Astana, Kazakhstan, ${ }^{8}$ Department of Internal Medicine, Second Medical Faculty, Motol, Prague, Czech Republic

Received December 27, 2016

Accepted January 9, 2017

\section{Summary}

Cardiovascular diseases are the most common cause of mortality and morbidity in most populations. As the traditional modifiable risk factors (smoking, hypertension, dyslipidemia, diabetes mellitus, and obesity) were defined decades ago, we decided to analyze recent data in patients who survived acute coronary syndrome (ACS). The Czech part of the study included data from 999 males, and compared them with the post-MONICA study (1,259 males, representing general population). The Lithuanian study included 479 male patients and 456 age-matched controls. The Kazakhstan part included 232 patients and 413 controls. In two countries, the most robust ACS risk factor was smoking (OR 3.85 in the Czech study and 5.76 in the Lithuanian study), followed by diabetes (OR 2.26 and 2.07) and hypertension (moderate risk elevation with OR 1.43 and 1.49). These factors did not influence the ACS risk in Kazakhstan. BMl had no significant effect on ACS and plasma cholesterol was surprisingly significantly lower $(\mathrm{P}<0.001)$ in patients than in controls in all countries $(4.80 \pm 1.11$ vs. $5.76 \pm 1.06 \mathrm{mmol} / \mathrm{l}$ in Czechs; $5.32 \pm 1.32$ vs. $5.71 \pm 1.08 \mathrm{mmol} / \mathrm{l}$ in Lithuanians; $4.88 \pm 1.05$ vs. $5.38 \pm 1.13 \mathrm{mmol} / \mathrm{l}$ in Kazakhs/Russians). Results from our study indicate substantial heterogeneity regarding major CVD risk factors in different populations with the exception of plasma total cholesterol which was inversely associated with ACS risk in all involved groups. These data reflect ethnical and geographical differences as well as changing pattern of cardiovascular risk profiles.

\section{Key words}

Acute coronary syndrome • Obesity • Hypertension • Cholesterol - Diabetes • Smoking • Prevalence

\section{Corresponding author}

J. A. Hubacek, IKEM-CEM-LMG, Videnska 1958/9, 14021 Prague 4, Czech Republic. Fax: +420 241721 574. E-mail: jahb@ikem.cz

\section{Introduction}

The etiology of atherosclerotic coronary disease is multifactorial. Aside from non-modifiable risk factors such as age, being male and genetic predisposition, many other risk factors could be managed by changes to individual life style and/or pharmacotherapy. More than 
200 of these risk factors have been described (Hopkins and Williams 1981), of which the most important are considered to be high plasma cholesterol level, hypertension, diabetes mellitus, smoking and overweight/ obesity. The definition of these risk factors was assessed decades ago and is originally based on data obtained from the Framingham study (Dawber et al. 1962). Data are available on the prevalence and changes of these risk factors in European populations thanks to the MONICA and post-MONICA studies (Keil 2005, Cifkova et al. 2010, Lindroth et al. 2014, Vikhireva et al. 2014), but much less evidence is available regarding the real pattern of risk factors in patients suffering from cardiovascular diseases (CVD).

In order to estimate further development in mortality and morbidity on CVD, it is of substantial importance to be aware of the prevalence of the traditional risk factors both in healthy populations and in patients with CVD.

We analyzed traditional CVD risk factors in four populations of males with acute coronary syndrome (ACS) from Prague, Czech Republic, Kaunas, Lithuanian Republic and Astana, Kazakhstan and compared them with control populations.

\section{Methods}

\section{Subject selection}

We collected data in three completely independent centers.

In the Czech group, 999 male patients (younger than 65 years) hospitalized between 2006 and 2012 at the coronary care unit of the Institute for Clinical and Experimental Medicine for acute coronary syndrome (ACS) (Hubáček et al. 2015, Hubáček et al. 2016) were included. As a controls, we used a $1 \%$ sample of the general population from the WHO MONICA study (MONItoring of CArdiovascular diseases (Tunstall-Pedoe et al. 2003) in 9 Czech regions) and a survey from 2000/2001 (1,259 males) was included.

In the Lithuanian group, 479 patients with ACS were enrolled in the study. The mean age of the patients was $59.9 \pm 11.0$ years, all of whom were admitted to the Department of Cardiology of the Lithuanian University of Health Sciences Hospital between 2007 and 2011.

The control group consisted of 456 males free from symptoms of IHD and stroke, matching the study group design according to age. The control group consisted of subjects from a random sample of the
Kaunas population screened within the international HAPPIE (Health, Alcohol and Psychosocial factors In Eastern Europe) project (Peasey et al. 2006), the CINDI (Countrywide Integrated Non-communicable Disease Intervention) project (Grabauskas et al. 2008) and the “Kaunas Healthy Ageing Study”.

In the Kazakhstan group, 232 male patients (aged 50-74 years) hospitalized between 2013 and 2015 at the coronary care unit of the Astana City Hospital \#2 for acute coronary syndrome were included in the analysis.

For the Kazakhstan control group, the study sample was randomly selected from registries of all inhabitants at local outpatient clinics. Persons in the age range 50-74 year were included. A total number of 416 male adults were used in the current analysis, excluding those who self-reported diagnosed CVD in the history (Supiyev et al. 2015, Supiyev et al. 2016). Excluded were also subjects with serious diseases (cancers, renal failure). In total, there were $63.7 \%$ of Kazakhs, $24.9 \%$ of Russians with $12.4 \%$ declaring the others ethnicities.

At all centre's, the patients completed a questionnaire and their lipoprotein parameters were measured in the local laboratory within $24 \mathrm{~h}$ of the onset of symptoms. ACS was defined according to the standard criteria based on clinical symptoms, ECG findings and cardiac-enzyme abnormalities.

The studies were performed in agreement with The Code of Ethics of the World Medical Association (Declaration of Helsinki) for experiments involving humans. All patients signed informed consent before they were included in the study.

\section{Definition of risk factors}

Basic/traditional risk factors were defined as follows: 1) current or past smokers; 2) body mass index (BMI) $\geq 25 \mathrm{~kg} / \mathrm{m}^{2}$; 3) hypertension (self-reported and/or antihypertensive treatment and/or blood pressure over 139/89; and 4) diabetes as self-reported diabetes and/or antidiabetic (also dietary) treatment. Both in controls and in patients, data were obtained from personal questionnaires completed under the supervision of a trained nurse prior to discharge. Diagnoses were determined by coronary care unit physicians, during which time anthropometric and biochemical parameters were reviewed.

Cholesterol and triglycerides (in fasting plasma, day after admission) were assessed using conventional 
enzymatic methods (reagents from Boehringer Mannheim Diagnostics and Hoffmann-La Roche).

\section{Statistical analyses}

Data from questionnaires and biochemical parameters were entered into the database. Statistical analysis was performed using standard statistical tests as follows: chi square test for categorical variables and ANOVA for continuous variables. As the study is focused on confirmation of the traditional CVD risk factors, no multivariate analysis has been performed. For adjustment purposes, we used ANCOVA for continuous variables and logistic regression for discrete variables. Odds ratios (OR) and $95 \%$ confidence intervals (CI) were calculated using http://www.hutchon.net/ ConfidOR.htm.

\section{Results}

\section{Czech branch}

We collected complete data from 999 males (93.2\% out of 1,072 hospitalized patients fulfilled the basal criteria; 55 refused to participate; and in the case of 18 patients, data were incomplete) with ACS. Controls were slightly but significantly $(\mathrm{P}<0.001)$ younger than patients (Table 1).

The largest difference between patients and controls was observed with regard to prevalence of smoking. Among the patients, only $14.9 \%$ were never smokers, in comparison to $40.3 \%$ in the general population ( $\mathrm{P}<0.0001$; OR (95 \% CI) 3.85 (3.12-4.73)).

The second major risk was associated with the prevalence of diabetes - there were twice as many diabetics $(\mathrm{P}<0.0001 ; 2.26(1.76-2.91))$ in patients (17.8\%) than in controls (8.9\%).

With regard to hypertension, a significant difference was observed only in the unadjusted model, but not after adjustment for age. Prevalence of overweight was almost identical between patients and controls.

Plasma cholesterol levels were significantly lower $(\mathrm{P}<0.001)$ in patients $(4.80 \pm 1.11 \mathrm{mmol} / \mathrm{l})$ than in controls $(5.76 \pm 1.06 \mathrm{mmol} / \mathrm{l})$. This difference remained significant even after the exclusion of patients (13.4\% were treated by statin or fibrate) and controls (8\%) on hypolipidemic treatment.

\section{Lithuanian branch}

This part of the study included 479 patients and
456 age matched controls (Table 2) and observations revealed similar results to those obtained in the Czech patient/control branch.

This part further underlines the importance of smoking as a major risk factor of ACS. Among the patients, $28.4 \%$ were never smokers, in comparison to $64.1 \%$ in the general population $(\mathrm{P}<0.0001)$, which means that the OR (95\% CI) associated with smoking was 5.76 (3.78-6.75).

Diabetes (OR 2.13, 95 \% CI 1.22-3.73) was the second most important risk factor, more than doubling the increase of risk.

Similar to the Czech data, hypertension (OR 1.49, 95 \% CI 1.03-2.16) had only a minor effect (but still significant at $\mathrm{P}=0.04$ ) and body weight had no effect $(\mathrm{P}=0.76)$.

Finally, total plasma cholesterol was also here significantly lower $(\mathrm{P}<0.001)$ in patients $(5.32 \pm 1.32 \mathrm{mmol} / \mathrm{l})$ than in controls $(5.71 \pm 1.08 \mathrm{mmol} / \mathrm{l})$.

\section{Kazakhstan branch}

Within the Kazakhstan subjects, the risk of myocardial infarction was not associated with any traditional risk factor (Table 3). The proportion of diabetes and obesity were even slightly higher among controls in the Kazakhstan group, and the hypertension and smoking were more prevalent in patients, but there were not statistically significant differences between the groups.

The difference between total cholesterol levels was in the similar direction $(\mathrm{P}<0.001)$ like in other two countries (Table 3). Surprisingly, the differences remain significant $(\mathrm{P}<0.05)$ even after dividing the group according the ethnicity - among Kazakhs, controls $(\mathrm{N}=267)$ had cholesterol $5.34 \pm 1.19 \mathrm{mmol} / \mathrm{l}$ and cases ( $\mathrm{N}=138) \quad 4.77 \pm 1.03 \mathrm{mmol} / \mathrm{l}$, and among Russians the values were $5.43 \pm 1.04 \mathrm{mmol} / \mathrm{l}$ for controls $(\mathrm{N}=89)$ vs. $4.99 \pm 1.04 \mathrm{mmol} / \mathrm{l}$ for cases $(\mathrm{N}=72)$.

\section{Discussion}

Our study analyzed the prevalence of the five most commonly examined risk factors of cardiovascular disease among males suffering from ACS. Some of our results are surprising, especially the (absence of) association of the total cholesterol and acute forms of ischemic heart disease. 
Table 1. Prevalence of traditional risk factors among Czech males with acute coronary syndrome and controls.

\begin{tabular}{lcccc}
\hline & Patients & Controls & P & $\mathbf{P}^{\#}$ \\
\hline$N$ & 999 & 1,259 & & \\
Age (years) & $54.7 \pm 8.0$ & $49.0 \pm 10.8$ & 0.001 & 0.001 \\
Total cholesterol (mmol/l) & $4.80 \pm 1.11$ & $5.76 \pm 1.06$ & 0.001 & 0.001 \\
Total cholesterol* (mmol/l) & $4.89 \pm 1.13$ & $5.75 \pm 1.06$ & 0.001 & 0.02 \\
Triglycerides (mmol/l) & $2.06 \pm 1.49$ & $1.97 \pm 1.28$ & n.s. & 0.02 \\
Triglycerides* (mmol/l) & $2.03 \pm 1.47$ & $1.94 \pm 1.24$ & n.s. & 0.0001 \\
Ever smokers (\%) & 85.1 & 59.7 & 0.00001 & 0.01 \\
Diabetes (\%) & 17.8 & 8.9 & 0.0005 & n.s. \\
Hypertension (\%) & 50.6 & 41.6 & 0.001 & n.s. \\
Overweight (\%) & 80.1 & 79.9 & 0.005 & - \\
Statin treatment (\%) & 13.4 & 8.0 & & - \\
\hline
\end{tabular}

* Patients $(\mathrm{N}=134)$ and controls $(\mathrm{N}=101)$ treated by statin or fibrate are excluded. ${ }^{*} \mathrm{P}$ adjusted for age.

Table 2. Prevalence of traditional risk factors among Lithuanian males with acute coronary syndrome and controls.

\begin{tabular}{lccc}
\hline & Patients & Control group & P value \\
\hline$N$ & 479 & 456 & 0.27 \\
Age (years) & $59.9 \pm 11.0$ & $59.1 \pm 10.6$ & 0.0001 \\
Total cholesterol (mmol/l) & $5.32 \pm 1.32$ & $5.71 \pm 1.08$ & 0.0001 \\
Triglycerides (mmol/l) & $1.74 \pm 1.60$ & $1.34 \pm 0.77$ & 0.0001 \\
Ever smokers (\%) & 71.6 & 35.9 & 0.005 \\
Diabetes (\%) & 10.6 & 6.8 & 0.05 \\
Hypertension (\%) & 82.3 & 74.6 & 0.76 \\
Overweight (\%) & 77.7 & 76.8 & 0.61 \\
Statin treatment (\%) & 6.3 & 5.6 & \\
\hline
\end{tabular}

Table 3. Prevalence of traditional risk factors among Kazakhstan males ( $63.7 \%$ Kazakhs and $24.9 \%$ Russians included) with acute coronary syndrome and controls.

\begin{tabular}{lccc}
\hline & Patients & Control group & P value \\
\hline$N$ & 232 & 416 & 0.27 \\
Age (years) & $59.9 \pm 6.9$ & $60.6 \pm 7.3$ & 0.001 \\
Total cholesterol (mmol/l) & $4.88 \pm 1.05$ & $5.38 \pm 1.13$ & 0.995 \\
Triglycerides (mmol/l) & $1.65 \pm 0.83$ & $1.65 \pm 1.32$ & 0.224 \\
Ever smokers (\%) & 74.2 & 69.7 & 0.555 \\
Diabetes (\%) & 12.6 & 14.2 & 0.127 \\
Hypertension (\%) & 59.4 & 53.1 & 0.250 \\
Overweight (\%) & 74.9 & 78.9 & 0.63 \\
Statin treatment (\%) & 7.1 & 9.0 & \\
\hline
\end{tabular}


It seems that only two risk factors for acute forms of ischemic heart disease are now considered important. These are: smoking and diabetes mellitus. Our study showed that smoking status was the most extreme factor, as only about $20 \%$ of all patients consisted of never smokers and, based on our results, smokers are about five times more likely to experience ACS than never smokers. Surprisingly, in Kazakhstan, these factors have not been associated with CVD risk.

The two other risk factors, namely hypertension and overweight/obesity, seemed to be of less importance. This is underlined by the fact that both factors were not significantly associated with ACS after adjustment for age in Czech Republic or Kazakhstan and that only a borderline significance was observed in the Lithuanian population. From the MONICA study, it is clear that the prevalence of hypertension in the general population is now lower than it was (Dawber et al. 1962, Cifkova et al. 2010, Lindroth et al. 2014, Vikhireva et al. 2014). As a consequence of the success of primary prevention, we detected relatively low differences in hypertension prevalence between patients and controls. However, this finding needs to be further interpreted very carefully. There was a higher prevalence of individuals treated with antihypertensive drugs in patients than in controls. Furthermore, as our blood pressure values were obtained on the second day of hospitalization, it is possible that they do not exactly reflect the values before the onset of ACS.

Also, based on the analysis of the prevalence of overweight, controls were not leaner than patients.

The most interesting finding was that ACS patients had lower plasma total cholesterol than controls, independently in all three different countries. This was valid even after exclusion of patients and controls on hypolipidemic treatment, and after adjustment for age. One of explanations is that plasma total cholesterol is going down as a consequence of acute myocardial infarction. Studies have detected a decrease of about $7 \%$ of total cholesterol after the onset of ACS (Wattanasuwan et al. 2001, Fresco et al. 2002). In a Czech branch, where we have for the majority of subjects both cholesterol values at admission and from fasting blood sampling, the identical decrease was obtained (Staněk et al. 2016). In this study, the total cholesterol values at admission were nonsignificantly lower than in age matched controls (Staněk et al. 2016). If we assume that the effect in all our populations is identical, then total plasma cholesterol would still not be a risk factor for cardiovascular disease, as expected.

Second explanation is unique role of LDL cholesterol and not total cholesterol. Unfortunately, calculating (using the Friedewald formula) precise values of LDL cholesterol in ACS patients through the hospitalization are not reliable. One of reasons is possibility that heparinization (as a standard approach in pre-hospital ACS patients care) results in a decrease of plasma triglyceride levels (Mulder et al. 1993) due to hydrolysis of TG-rich lipoprotein particles. This could also modify LDL levels in not well predictable manner.

In the literature, the fact that total plasma cholesterol levels are lower in patients with ACS/MI is often "hidden" and not clearly presented. Other publications (for example see Pérez-Hernández et al. 2012) have confirmed the risk associated with dyslipidemia, but not with plasma total cholesterol. Dyslipidemia is defined as abnormal values of total plasma/LDL cholesterol, HDL cholesterol and triglycerides. In most subjects, in fact, elevated plasma TG values are the reason of dyslipidemia. As prevalence of obesity and diabetes mellitus is increasing, elevated plasma triglycerides and associated lipid disorders (small atherogenic LDL particles, remnant lipoprotein particles) are becoming the essence of atherogenic dyslipidemia. Similarly, in our two populations, TG values were significantly higher in patients than in controls. In agreement with this finding, plasma TG values, rather than plasma TC values are predictors of total mortality (Hubáček 2015, Liu et al. 2013, Pikhart et al. 2015, Pit'ha et al. 2015).

Even the global INTERHEART study recognize as risk factor of myocardial infarction the high ApoB/ApoA1 ratio, which was considered to be superior to commonly used cholesterol derived values and ratios (Mc Queen et al. 2008), one of reasons was that not all samples have been available after fasting status, reflecting to certain extent also settings of our study.

It should be noted that our results are not unique (Morales-Suarez-Varela et al. 2011, NikolajevićStarčević and Petrovič 2013). In fact, some other recent studies have recorded similar results, questioning the health risks associated with elevated plasma cholesterol levels, especially in the case, if they have been focused on the mortality data. For example, a study by Tamosiunas et al. (2014) presented the results from the Lithuanian MONICA and HAPIEE studies and concluded that CVD mortality was not associated with plasma cholesterol in males or in females and that plasma 
cholesterol below $5.2 \mathrm{mmol} / \mathrm{l}$ was associated with enhanced risk of CVD. Also, values of adjusted hazard ratios obtained from the NHANES III study point to the insignificance of plasma cholesterol levels in cases where cardiovascular or total mortality was analyzed (Yang et al. 2012). Based on their results, researchers from the HUNT2 study (Petursson et al. 2012) even concluded that plasma cholesterol levels should be omitted from cardiovascular risk calculation. Similarly, the Seoul Male Cohort Study (Kim et al. 2013) found that cholesterol was not associated with CVD mortality and, finally, a study of almost 100000 Chinese subjects found no effect of plasma cholesterol on cardiovascular or total mortality (Liu et al. 2014). It should be noted that these studies also did not confirm the risks associated with higher BMI values.

Thus, we can conclude that the importance of total plasma cholesterol as a discriminating risk factor of CVD is becoming less and less important at least at the population level and other lipid parameters - mainly triglycerides and possibly LDL and/or non-HDL cholesterol are of importance. This may also be further supported by the fact that, first, plasma levels of lipids have significantly declined over recent decades for about $20 \%$ of the general population (Cífková et al. 2010); therefore, a much higher proportion of the population now corresponds to recommended values. A further explanation could be linked to the role played by higher levels of remnant lipoprotein particles and their cholesterol content, which are not detected in the fasting state (Varbo et al. 2013, Varbo et al. 2015), but which are reflected in higher plasma triglycerides.

Despite the continuous decline in cardiovascular mortality since 2000 in all EU countries, CVD is still responsible for almost $40 \%$ of deaths in these countries (OECD 2016). Despite the refinement of the ACS criteria (Thygesen et al. 2012), no significant development has been observed over the last forty years in relation to the definition of CVD risk factors. For example, the selection of risk factors is based on the Framingham offspring study (Dawber et al. 1962). But the population's prevalence for most of these CVD risk factors (as defined more than a half of the century) has significantly changed (Keil 2005, Cifkova et al. 2010, Lindroth et al. 2014, Vikhireva et al. 2014). We strictly keep to the "big five", while failing to acknowledge the prevalence and importance for these factors to rise in some cases (smoking and diabetes) and decline in others (BMI and plasma cholesterol).

As a consequence, estimating CVD risk might be misleading when based on total plasma cholesterol levels as the main risk factor. Even though we are aware of the limitations of this cross-sectional study, similar findings from our three independent centers, along with further published studies, allow us to propose a more cautious approach to the development of algorithms based on cardiovascular risk factors established decades ago. New prospective studies are definitely needed to confirm this important change in traditional cardiovascular risk factors.

\section{Conflict of Interest}

There is no conflict of interest.

\section{Acknowledgements}

Supported by the Ministry of Health of the Czech Republic - conceptual development of the research organization ("Institute for Clinical and Experimental Medicine - IKEM, IN 00023001”); by programme targeted funding from the Ministry of Education and Science of the Republic of Kazakhstan (Agreement \#409/037-2014, March 07 2014, \#089-2014, May 13 2014); by Talap scholarship awarded to Adil Supiyev by the Nazarbayev University and by grants from the Welcome Trust (grant no. 081081/Z/06/Z), the US National Institute on Aging (grant no. 1R0I AG23522), and by the MacArthur Foundation (Health and Social Upheaval network) (HAPIEE study).

\section{References}

CÍFKOVÁ R, ŠKODOVÁ Z, BRUTHANS J, ADÁMKOVÁ V, JOZÍFOVÁ M, GALOVCOVÁ M, WOHLFAHRT P, KRAJCOVIECHOVÁ A, POLEDNE R, STÁVEK P, LÁNSKÁ V: Longitudinal trends in major cardiovascular risk factors in the Czech population between 1985 and 2007/8. Czech MONICA and Czech post-MONICA. Atherosclerosis 211: 676-681, 2010.

DAWBER TR, KANDEL WB, REVOTSKIE N, KAGAN A: The epidemiology of coronary heart disease - the Framingham enquiry. Proc R Soc Med 55: 265-271, 1962. 
FRESCO C, MAGGIONI AP, SIGNORINI S, MERLINI PA, MOCARELLI P, FABBRI G, LUCCI D, TUBARO M, GATTONE M, SCHWEIGER C; LATIN INVESTIGATORS: Variations in lipoprotein levels after myocardial infarction and unstable angina: the LATIN trial. Ital Heart J 3: 587-592, 2002.

GRABAUSKAS V, KLUMBIENE J, PETKEVICIENE J, PETRAUSKIENE A, TAMOSIŪNAS A, KRIAUCIONIENE V, RAMAZAUSKIENE V: Risk factors for noncommunicable diseases in Lithuanian rural population: CINDI survey 2007. Medicina (Kaunas) 44: 633-639, 2008.

HOPKINS PN, WILLIAMS RR: A survey of 246 suggested coronary risk factors. Atherosclerosis 40: 1-52, 1981.

HUBÁČEK JA: High cholesterol is not associated with increased mortality (in Czech). Hyper Kardiovask Prevence 3 : 58-62, 2015.

HUBACEK JA, STANĚK V, GEBAUEROVÁ M, POLEDNE R, ASCHERMANN M, SKALICKÁ H, MATOUŠKOVÁ J, KRUGER A, PĚNIČKA M, HRABÁKOVÁ H, VESELKA J, HÁJEK P, LÁNSKÁ V, ADÁMKOVÁ V, PIŤHA J: Rs6922269 marker at the MTHFD1L gene predict cardiovascular mortality in males after acute coronary syndrome. Mol Biol Rep 42: 1289-1293, 2015.

HUBACEK JA, VRABLIK M, DLOUHA D, STANEK V, GEBAUEROVA M, ADAMKOVA V, CESKA R, DOSTÁlOVÁ G, LINHART A, VITEK L, PITHA J: Gene variants at FTO, 9p21, and 2q36.3 are age-independently associated with myocardial infarction in Czech men. Clin Chim Acta 454: 119-123, 2016.

KEIL U: The Worldwide WHO MONICA Project: results and perspectives. Gesundheitswesen 67 (Suppl 1): S38-S45, 2005.

KIM JY, KO YJ, RHEE CW, PARK BJ, KIM DH, BAE JM, SHIN MH, LEE MS, LI ZM, AHN YO: Cardiovascular health metrics and all-cause and cardiovascular disease mortality among middle-aged men in Korea: the Seoul male cohort study. J Prev Med Public Health 46: 319-328, 2013.

LINDROTH M, LUNDQVIST R, LILJA M, ELIASSON M: Cardiovascular risk factors differ between rural and urban Sweden: the 2009 Northern Sweden MONICA cohort. BMC Public Health 14: 825, 2014.

LIU J, ZENG FF, LIU ZM, ZHANG CX, LING WH, CHEN YM: Effect of blood triglycerides on cardiovascular and all-cause mortality: a systematic review and meta-analysis of 61 prospective studies. Lipids Health Dis 12: 159, 2013.

LIU Y, CHI HJ, CUI LF, YANG XC, WU YT, HUANG Z, ZHAO HY, GAO JS, WU SL, CAI J: The ideal cardiovascular health metrics associated inversely with mortality from all causes and cardiovascular diseases among adults in a Northern Chinese industrial city. PloS One 9: e89161, 2014.

MCQUEEN MJ, HAWKEN S, WANG X, OUNPUU S, SNIDERMAN A, PROBSTFIELD J, STEYN K, SANDERSON JE, HASANI M, VOLKOVA E, KAZMI K, YUSUF S, INTERHEART STUDY INVESTIGATORS: Lipids, lipoproteins, and apolipoproteins as risk markers of myocardial infarction in 52 countries (the INTERHEART study): a case-control study. Lancet 372: 224-233, 2008.

MORALES-SUAREZ-VARELA MM, RIERA-FORTUNY C, MANSEGO ML, MARTINEZ-TRIGUERO ML, CHAVES FJ, MARTIN-MORENO JM, BAÑULS C, HERNANDEZ-MIJARES A: Association between AT C573T polymorphism and cardiovascular risk factors in myocardial infarction. Cardiovasc Pathol 20: 156-161, 2011.

MULDER M, LOMBARDI P, JANSEN H: Low density lipoprotein receptor internalizes low density and very low density lipoproteins that are bound to heparan sulfate proteoglycans via lipoprotein lipase. J Biol Chem 268: 9369-9375, 1993.

NIKOLAJEVIĆ-STARČEVIĆ J, PETROVIČ D: The a1/a2 polymorphism of the glycoprotein IIIa gene and myocardial infarction in Caucasians with type 2 diabetes. Mol Biol Rep 40: 2077-2081, 2013.

OECD: Health at a Glance: Europe 2016. OECD Publishing, http://www.oecd-ilibrary.org/docserver/ download/8116231e.pdf?expires=1485792184\&id=id\&accname=guest\&checksum=A7E306D1807F1A078B4 FA9FEEB4F2F2C (accessed January 2017)

PEASEY A, BOBAK M, KUBINOVA R, MALYUTINA S, PAJAK A, TAMOSIUNAS A, PIKHART H, NICHOLSON A, MARMOT M: Determinants of cardiovascular disease and other non-communicable diseases in Central and Eastern Europe: rationale and design of the HAPIEE study. BMC Public Health 6: 255, 2006. 
PÉREZ-HERNÁNDEZ N, VARGAS-ALARCÓN G, MARTÍNEZ-RODRÍGUEZ N, MARTÍNEZ-RÍOS MA, PEÑA-DUQUE MA, PEÑA-DÍAZ ADE L, VALENTE-ACOSTA B, POSADAS-ROMERO C, MEDINA A, RODRÍGUEZ-PÉREZ JM: The matrix metalloproteinase 2-1575 gene polymorphism is associated with the risk of developing myocardial infarction in Mexican patients. J Atheroscler Thromb 19: 718-727, 2012.

PETURSSON H, SIGURDSSON JA, BENGTSSON C, NILSEN TI, GETZ L: Is the use of cholesterol in mortality risk algorithms in clinical guidelines valid? Ten years prospective data from the Norwegian HUNT 2 study. J Eval Clin Pract 18: 159-168, 2012.

PIKHART H, HUBÁČEK JA, PEASEY A, KUBÍNOVÁ R, BOBÁK M: Association between fasting plasma triglycerides, all-cause and cardiovascular mortality in Czech population. Results from the HAPIEE study. Physiol Res 64 (Suppl 3): S355-S361, 2015.

PIŤHA J, KOVÁŘ J, BLAHOVÁ T: Fasting and nonfasting triglycerides in cardiovascular and other diseases. Physiol Res 64 (Suppl 3): S323-S330, 2015.

STANĚK V, GEBAUEROVÁ M, PIŤHA J, POLEDNE R, LÁNSKÁ V, CÍFKOVÁ R, MRÁZKOVÁ J, KETTNER J: The risk profile of patients with acute coronary syndrome treated at IKEM between 2006 and 2013. Cor Vasa in press 2016, http://dx.doi.org/10.2016/j.crvasa.2016.11.013

SUPIYEV A, KOSSUMOV A, UTEPOVA L, NURGOZHIN T, ZHUMADILOV Z, BOBAK M: Prevalence, awareness, treatment and control of arterial hypertension in Astana, Kazakhstan. A cross-sectional study. Public Health 129: 948-953, 2015.

SUPIYEV A, KOSSUMOV A, KASSENOVA A, NURGOZHIN T, ZHUMADILOV Z, PEASEY A, BOBAK M: Diabetes prevalence, awareness and treatment and their correlates in older persons in urban and rural population in the Astana region, Kazakhstan. Diabetes Res Clin Pract 112: 6-12, 2016.

TAMOSIUNAS A, LUKSIENE D, BACEVICIENE M, BERNOTIENE G, RADISAUSKAS R, MALINAUSKIENE V, KRANCIUKAITE-BUTYLKINIENE D, VIRVICIUTE D, PEASEY A, BOBAK M: Health factors and risk of all-cause, cardiovascular, and coronary heart disease mortality: findings from the MONICA and HAPIEE studies in Lithuania. PLoS One 9: e114283, 2014.

THYGESEN K, ALPERT JS, JAFFE AS, SIMOONS ML, CHAITMAN BR, WHITE HD: Task Force for the Universal Definition of Myocardial Infarction. Third universal definition of myocardial infarction. Nat Rev Cardiol 9: 620-633, 2012.

TUNSTALL-PEDOE H, KUULASMAA K, TOLONEN H, DAVIDSON M, MENDIS S: MONICA monograph and multimedia sourcebook. TUNSTAL-PEDOE H (ed.), Geneva, World Health Organisation, 2003.

VARBO A, BENN M, TYBJÆRG-HANSEN A, JØRGENSEN AB, FRIKKE-SCHMIDT R, NORDESTGAARD BG: Remnant cholesterol as a causal risk factor for ischemic heart disease. J Am Coll Cardiol 61: 427-436, 2013.

VARBO A, FREIBERG JJ, NORDESTGAARD BG: Extreme nonfasting remnant cholesterol vs extreme LDL cholesterol as contributors to cardiovascular disease and all-cause mortality in 90,000 individuals from the general population. Clin Chem 61: 533-543, 2015.

VIKHIREVA O, PAJAK A, BRODA G, MALYUTINA S, TAMOSIUNAS A, KUBINOVA R, SIMONOVA G, SKODOVA Z, BOBAK M, PIKHART H: SCORE performance in Central and Eastern Europe and former Soviet Union: MONICA and HAPIEE results. Eur Heart J 35: 571-577, 2014.

WATTANASUWAN N, KHAN IA, GOWDA RM, VASAVADA BC, SACCHI TJ: Effect of acute myocardial infarction on cholesterol ratios. Chest 120: 1196-1199, 2001.

YANG Q, COGSWELL ME, FLANDERS D, HONG Y, ZHANG Z, LOUSTALOT F, GILLESPIE C, MERRITT R, HU FB: Trends in cardiovascular health metrics and association with all-cause and CVD mortality among US adults. JAMA 307: 1273-1283, 2012. 